\title{
TITLE:
}

\section{Gallium nitride thin films deposited by radio-frequency magnetron sputtering}

AUTHOR(S):

Maruyama, T; Miyake, $\mathrm{H}$

\section{CITATION:}

Maruyama, T ...[et al]. Gallium nitride thin films deposited by radio-frequency magnetron sputtering. JOURNAL OF VACUUM SCIENCE \& TECHNOLOGY A 2006, 24(4): 1096-1099

\section{ISSUE DATE:}

2006

URL:

http://hdl.handle.net/2433/43541

\section{RIGHT:}

Copyright 2006 American Vacuum Society 


\title{
Gallium nitride thin films deposited by radio-frequency magnetron sputtering
}

\author{
Toshiro Maruyama ${ }^{\text {a) }}$ and Hidetomo Miyake \\ Department of Chemical Engineering, Graduate School of Engineering, Kyoto University, \\ Kyoto 615-8510, Japan
}

(Received 29 December 2005; accepted 4 May 2006; published 15 June 2006)

\begin{abstract}
Effects of self-induced negative bias in radio-frequency ( $\mathrm{rf}$ ) sputtering on the structure of the deposited film are discussed on the basis of the measured characteristics of the gallium nitride $(\mathrm{GaN})$ films. A powdered GaN target was sputtered by either argon $(\mathrm{Ar})$ or nitrogen $\left(\mathrm{N}_{2}\right)$ gas to investigate the effects of the sputtering. When sputtering with $\mathrm{Ar}$ gas, the resputtering due to the ion bombardments produces a film deficient in nitrogen with poor crystallinity. The ion bombardment eventually destroys the crystal structure producing a black amorphous film caused by gallium atoms forming clusters. Alternatively, when sputtering with $\mathrm{N}_{2}$ gas, the activated nitrogen atmosphere enhances nitrogen incorporation and prevents the destruction of the crystal structure, making the film stoichiometric. To obtain high crystallinity, the effect of the self-induced negative bias should be minimized by decreasing the rf power and increasing the total pressure. (C) 2006 American Vacuum Society. [DOI: 10.1116/1.2208988]
\end{abstract}

\section{INTRODUCTION}

Gallium nitride $(\mathrm{GaN})$ is a direct energy gap III-V semiconductor. A single crystal gallium nitride is grown at a temperature generally above $800{ }^{\circ} \mathrm{C}$, on sapphire or silicon carbide substrate. At present, polycrystalline material is prevalent when growing on temperature sensitive substrates, such as glass or silicon at low growth temperatures. For many applications, however, polycrystalline material may be of sufficient quality for device use, such as thin film transistor displays and solar cells which utilize glass substrate. Extending the applications of $\mathrm{GaN}$ and exploiting its desirable material properties require development of low-temperature growth processes, such as sputtering.

Aside from the pioneering work of Hovel and Cuomo, ${ }^{1}$ only a handful of research projects have been carried out on the sputter growth of GaN..$^{2-9}$ All the research utilized reactive sputtering with a gallium $(\mathrm{Ga})$ target, and most used a radio-frequency (rf) sputtering source. ${ }^{1-6,9}$ Vossen and Cuomo ${ }^{10}$ reported that in glow discharge sputtering systems the substrates are nearly always subject to a self-induced negative bias, resulting in ion bombardment of the film. This, in turn, leads to the resputtering of the atomic nitrogen from the film in sputter deposition of nitride film.

In this article, the conditions for obtaining films of high crystallinity are discussed on the basis of the measured characteristics of the GaN films. In rf sputtering, a powdered $\mathrm{GaN}$ target was sputtered with either argon (Ar) or nitrogen $\left(\mathrm{N}_{2}\right)$ gas to determine the effects of sputtering.

\section{EXPERIMENT}

For depositing GaN films, rf (13.5 MHz) magnetron sputtering equipment ${ }^{11}$ (Osaka Vacuum, Ltd.) was used with a $99.99 \%$ pure $\mathrm{GaN}$ powder target. The rf powers were

${ }^{a)}$ Electronic mail: maruyama@cheme.kyoto-u.ac.jp
50-300 W, the sputtering gases were $99.999 \%$ pure nitrogen and $99.999 \%$ pure argon, and their flow rate was 5-358 SCCM (SCCM denotes standard cubic centimeter per minute at STP) in the deposition chamber. The separation distance between the substrate and the target was $48 \mathrm{~mm}$. The chamber vacuum pressure prior to growth was less than $2.0 \times 10^{-6}$ Torr. The total sputtering pressure was 0.59-200 mTorr. A $76 \times 26 \mathrm{~mm}^{2}$ borosilicate glass plate was used as the substrates. Films were deposited on an unheated $\left(90{ }^{\circ} \mathrm{C}\right)$ or a heated $\left(200\right.$ and $\left.300{ }^{\circ} \mathrm{C}\right)$ substrate.

The crystal structure of the film was analyzed by the x-ray diffraction (XRD) method (Rigaku RINT 1400-TFD) with $\mathrm{Cu} K \alpha$ radiation. The optical transmission of the film was measured with a spectrophotometer (Perkin-Elmer Lambda 19). The refractive indices (at wavelength $>600 \mathrm{~nm}$ ) were estimated from the fringe pattern of the transmission spectrum. ${ }^{12}$ In the measurements for obtaining absorption coefficient of the film, a blank glass substrate was inserted into the reference beam path of the spectrophotometer. The optical energy gap for the GaN film is extracted from Tauc plots of $\alpha^{2}$ vs $h \nu$, where $\alpha$ is the absorption coefficient. The binding energy and composition of the film were measured with-

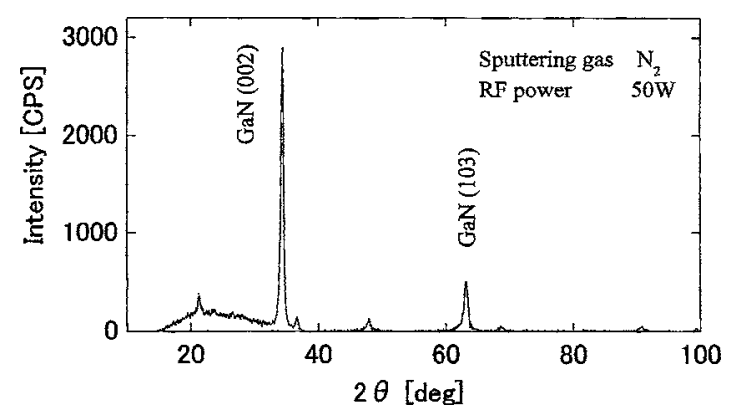

FIG. 1. X-ray diffraction pattern of the film deposited using $\mathrm{N}_{2}$ gas at a rf power of $50 \mathrm{~W}$ and total pressure of $2.3 \mathrm{mTorr}$. 


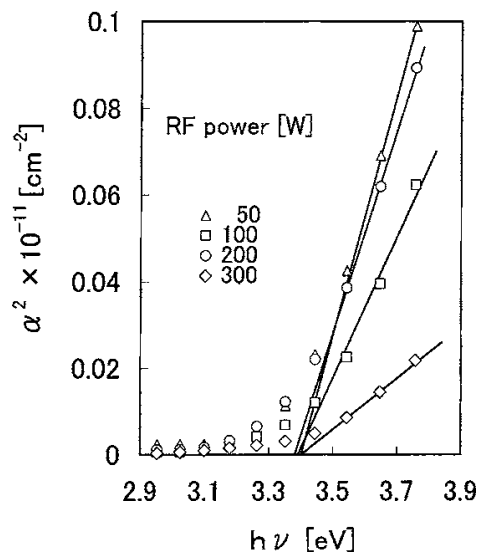

FIG. 2. Tauc plot of the films deposited using $\mathrm{N}_{2}$ gas at total pressure of 2.3 mTorr and various rf powers.

out Ar ion etching by x-ray photoelectron spectroscopy (Shimadzu ESCA 750) with $\operatorname{Mg} K \alpha$ excitation. To do this the films were deposited on (100) silicon single crystal substrates (Toshiba Ceramics Co., Ltd.). The composition of the film was expressed as the atomic ratio of nitrogen to gallium.

\section{RESULTS AND DISCUSSION}

The GaN films were light yellow in color, highly transparent, and electrically highly resistive. The crystal structure of the film strongly depended on both the sputtering gas and the rf power. First, consider the crystal structure of a film deposited on an unheated substrate at pressure of $2.3 \mathrm{mTorr}$ with $\mathrm{N}_{2}$ as a sputtering gas. Figure 1 shows the $\mathrm{x}$-ray diffraction pattern of a film for a rf power of $50 \mathrm{~W}$. The appearance of (002) and (103) peaks indicates that the film is composed of crystallite GaN with a hexagonal wurtzite structure with strong (002) plane texturing. Figure 2 shows the Tauc plot of films prepared at various rf powers. A linear relationship is obtained when $\alpha^{2}$ is plotted against photon energy, $h \nu$, indicating that the absorption edge is due to a direct transition. The intercept with the abscissa gives the optical energy gap, $E_{g}$, of about $3.4 \mathrm{eV}$ for the polycrystalline film. It agrees well with reported values, i.e., $3.2-3.4 \mathrm{eV}$ for polycrystalline $^{2-4}$ and $3.39 \mathrm{eV}$ for single crystal material. ${ }^{13}$ Table I lists the characteristics of the GaN film prepared on

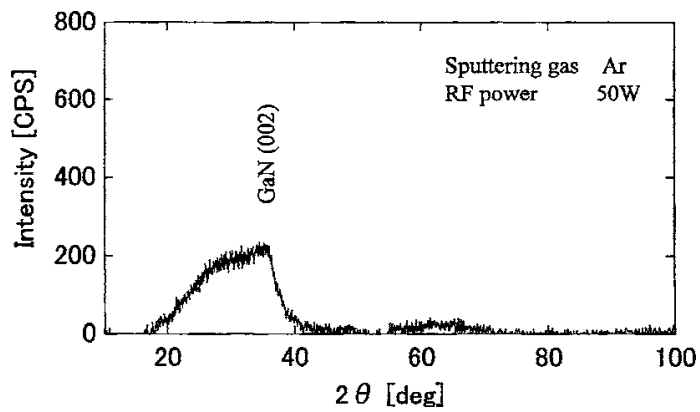

FIG. 3. X-ray diffraction pattern of the GaN film deposited using Ar gas at a rf power of $50 \mathrm{~W}$ and total pressure of $2.3 \mathrm{mTorr}$.

an unheated substrate at various rf powers. Also shown in the table are the lattice constants for the GaN powder. The films were polycrystalline. The atomic ratios are close to stoichiometric, and the refractive indices are close to the reported values, i.e., $2.1-2.3$ for polycrystalline ${ }^{1}$ and 2.33 for single crystal material. ${ }^{14}$

Next, consider the crystal structure of a film deposited on an unheated substrate at pressure of 2.3 mTorr using $\mathrm{Ar}$ as the sputtering gas. Figure 3 shows the XRD pattern of the film deposited at a rf power of $50 \mathrm{~W}$. The crystallinity appears poor in comparison with a film deposited using $\mathrm{N}_{2}$ (see Fig. 1). Table II lists the material and characteristics of the film deposited at various of powers. The atomic ratios are less than stoichiometric. While the films deposited at rf powers of 50 and $100 \mathrm{~W}$ are polycrystalline $\mathrm{GaN}$ of poor crystallinity, the films prepared at rf powers of 200 and $300 \mathrm{~W}$ are amorphous. In addition, the energy gaps of these films were 0 or negative. These facts indicate that the films are not $\mathrm{GaN}$. The mechanism forming these films is explained in the following.

The self-induced negative bias of the substrate due to the floating potential increases with increasing rf power, and consequently the ion bombardment of the substrate increases the resputtering of atomic nitrogen from the substrate. Eventually this effect becomes large enough to destroy the structure of the film. When sputtering with Ar gas, the resputtering makes the film deficient in nitrogen with poor crystallinity, and produces a black colored amorphous film in which $\mathrm{Ga}$ atoms have formed clusters. On the other hand,

TABLE I. rf power dependence of the characteristics of a $\mathrm{GaN}$ film deposited on an unheated substrate using $\mathrm{N}_{2}$ gas at total pressure of 2.3 mTorr.

\begin{tabular}{|c|c|c|c|c|c|}
\hline \multirow[b]{2}{*}{$\begin{array}{l}\text { rf power } \\
\text { (W) }\end{array}$} & \multirow[b]{2}{*}{$\mathrm{N} / \mathrm{Ga}$} & \multirow[b]{2}{*}{$\begin{array}{c}\text { Energy gap } \\
(\mathrm{eV})\end{array}$} & \multirow[b]{2}{*}{$\begin{array}{l}\text { Refractive } \\
\text { index }\end{array}$} & \multicolumn{2}{|c|}{ Lattice constant } \\
\hline & & & & $\begin{array}{c}a \\
(\AA)\end{array}$ & $\begin{array}{c}c \\
(\AA)\end{array}$ \\
\hline 50 & 1.05 & 3.40 & 2.20 & 3.201 & 5.204 \\
\hline 100 & 1.28 & 3.39 & 2.19 & 3.319 & 5.239 \\
\hline 200 & 1.05 & 3.38 & 2.17 & 3.227 & 5.318 \\
\hline \multirow[t]{2}{*}{300} & 0.97 & 3.40 & 2.00 & 3.221 & 5.236 \\
\hline & & & Powder & 3.186 & 5.178 \\
\hline
\end{tabular}


TABLE II. RF power dependence of the characteristics of the film deposited on an unheated substrate using Ar gas at total pressure of 2.3 mTorr.

\begin{tabular}{rcccc}
\hline \hline $\begin{array}{c}\text { rf power } \\
(\mathrm{W})\end{array}$ & Material & N/Ga & $\begin{array}{c}\text { Energy gap } \\
(\mathrm{eV})\end{array}$ & Refractive index \\
\hline 50 & $\mathrm{GaN}$ & 0.74 & 3.49 & 2.12 \\
100 & $\mathrm{GaN}$ & 0.61 & 3.42 & 1.97 \\
200 & $\cdots$ & 0.83 & $\cdots$ & $\cdots$ \\
300 & $\ldots$ & 0.54 & $\cdots$ & $\cdots$ \\
\hline \hline
\end{tabular}

TABLE III. Total pressure dependence of the characteristics of the film deposited on an unheated substrate using Ar gas at a rf power of $200 \mathrm{~W}$.

\begin{tabular}{cccc}
\hline \hline $\begin{array}{c}\text { Total pressure } \\
(\mathrm{mT} \text { Torr })\end{array}$ & Material & $\begin{array}{c}\text { Deposition rate } \\
\left(\mathrm{nm} \mathrm{h}^{-1}\right)\end{array}$ & $\mathrm{N} / \mathrm{Ga}$ \\
\hline 2.3 & $\ldots$ & 938 & 0.83 \\
11.8 & $\ldots$ & 826 & 0.65 \\
20 & $\ldots$ & 609 & 0.38 \\
30 & $\ldots$ & 373 & 0.23 \\
50 & $\mathrm{GaN}$ & 208 & 0.51 \\
100 & $\mathrm{GaN}$ & 90.8 & 0.65 \\
200 & $\mathrm{GaN}$ & 29.2 & 0.56 \\
\hline \hline
\end{tabular}

TABLE IV. Total pressure dependence of the characteristics of a GaN film deposited on an unheated substrate using $\mathrm{N}_{2}$ gas at a rf power of $200 \mathrm{~W}$.

\begin{tabular}{ccccc}
\hline \hline $\begin{array}{c}\text { Total pressure } \\
(\mathrm{mTorr})\end{array}$ & $\begin{array}{c}\text { Deposition rate } \\
\left(\mathrm{nm} \mathrm{h}^{-1}\right)\end{array}$ & $\mathrm{N} / \mathrm{Ga}$ & Crystallinity & $\begin{array}{c}\text { Integrated } \\
\text { intensity } \\
\text { (counts/s deg) }\end{array}$ \\
\hline 2.3 & 176.6 & 1.05 & Polycrystalline & 808 \\
20 & 77.3 & 1.38 & Polycrystalline & 262 \\
30 & 49.0 & 1.09 & Amorphous & \\
50 & 41.6 & 0.58 & Amorphous & \\
100 & 30.5 & 0.54 & Amorphous & \\
\hline \hline
\end{tabular}

when sputtering with $\mathrm{N}_{2}$ gas, the activated nitrogen atmosphere enhances nitrogen incorporation and prevents the destruction of the crystal structure, making the film stoichiometric with a high degree of crystallinity.

According to Vossen and Cuomo, ${ }^{10}$ the magnitude of the self-induced negative bias depends on both rf power and total pressure, i.e., it decreases with decreasing rf power and increasing total pressure. In the following section, conditions that suppress the self-induced negative bias are discussed on the basis of the crystallinity of the deposited film. First, the dependence on total pressure is discussed for a fixed rf power, $200 \mathrm{~W}$. Table III lists the material, deposition rate, and composition of the films deposited on an unheated substrate using $\mathrm{Ar}$ gas at total pressures ranging from 2.3 to 200 mTorr. Table IV lists the deposition rate and characteristics of the GaN films deposited on an unheated substrate using $\mathrm{N}_{2}$ gas at various total pressures. While all the films are $\mathrm{GaN}$ when $\mathrm{N}_{2}$ is used as the sputtering gas, $\mathrm{GaN}$ films are not obtained when sputtering with Ar gas (see Table III) at total pressure below 30 mTorr due to the effect of the self-induced negative bias. A transparent GaN film is obtained at total pressures above 50 mTorr, where the effect is suppressed. However, the films are nitrogen deficient and amorphous. Table IV shows that the GaN films deposited with $\mathrm{N}_{2}$ gas are amorphous at total pressures above 30 mTorr. At higher total pressure used to suppress the floating potential, the kinetic energies of the $\mathrm{Ga}$ and $\mathrm{N}$ atoms are reduced due to collision with molecular nitrogen, and become too small to produce crystalline material.

Table $\mathrm{V}$ lists the deposition conditions and characteristics of the GaN films deposited on an unheated substrate using $\mathrm{N}_{2}$ gas at $\mathrm{rf}$ power of $50 \mathrm{~W}$, which was the minimum power used to determine the effect of the self-induced negative bias. Also shown in Table $\mathrm{V}$ are other characteristic values of the crystal structure, i.e., the texture coefficient ${ }^{15}$ for (002) peak, the full width at half maximum (FWHM) of the (002) peak, and the lattice constants. All the films were polycrystalline

TABLE V. Total pressure dependence of the characteristics of a GaN film deposited on unheated and heated substrates using $\mathrm{N}_{2}$ gas at a rf power of $50 \mathrm{~W}$.

\begin{tabular}{|c|c|c|c|c|c|c|c|c|}
\hline \multirow{2}{*}{$\begin{array}{c}\text { Total } \\
\text { pressure } \\
\text { (mTorr) }\end{array}$} & \multirow{2}{*}{$\begin{array}{c}\text { Substrate } \\
\text { temperature } \\
\left({ }^{\circ} \mathrm{C}\right)\end{array}$} & \multirow{2}{*}{$\begin{array}{c}\text { Deposition } \\
\text { rate } \\
\left(\mathrm{nm} \mathrm{h}^{-1}\right)\end{array}$} & \multirow[b]{2}{*}{$\mathrm{N} / \mathrm{Ga}$} & \multirow{2}{*}{$\begin{array}{c}\text { Integrated } \\
\text { intensity } \\
\text { (counts/s deg) }\end{array}$} & \multirow[b]{2}{*}{$\begin{array}{c}\text { Texture } \\
\text { coefficient }\end{array}$} & \multirow[b]{2}{*}{$\begin{array}{c}\text { FWHM } \\
(\text { deg })\end{array}$} & \multicolumn{2}{|c|}{ Lattice constant } \\
\hline & & & & & & & $\begin{array}{c}a \\
(\AA)\end{array}$ & $\begin{array}{c}c \\
(\AA)\end{array}$ \\
\hline 0.59 & 90 & 66.8 & 1.41 & 953 & 1.41 & 0.546 & 3.2151 & 5.2216 \\
\hline 2.3 & 90 & 40.7 & 1.05 & 1430 & 1.80 & 0.451 & 3.2013 & 5.2038 \\
\hline 2.3 & 200 & 38.3 & 1.17 & 1049 & 1.84 & 0.428 & 3.1975 & 5.2038 \\
\hline 2.3 & 300 & 41.0 & 1.11 & 686 & 1.95 & 0.619 & 3.2274 & 5.2512 \\
\hline 10 & 90 & 16.8 & 1.29 & 708 & 1.88 & 0.375 & 3.1865 & 5.1460 \\
\hline 20 & 90 & 17.0 & 1.05 & 2521 & 1.72 & 0.382 & 3.1827 & 5.1748 \\
\hline 20 & 200 & 15.8 & 1.22 & 3767 & 1.80 & 0.374 & 3.1960 & 5.1806 \\
\hline 20 & 300 & 11.8 & 1.30 & 3790 & 1.87 & 0.372 & 3.1918 & 5.1892 \\
\hline 30 & 90 & 12.1 & 0.91 & 3720 & 1.92 & 0.373 & 3.2174 & 5.1834 \\
\hline 30 & 300 & 13.8 & 1.22 & 3495 & 1.90 & 0.380 & 3.2564 & 5.2126 \\
\hline 35 & 90 & 13.4 & 0.95 & 304 & 0.93 & 1.169 & 3.1825 & 5.1892 \\
\hline 40 & 90 & 11.3 & 0.80 & 164 & 0.35 & 1.108 & 3.1676 & 5.2422 \\
\hline
\end{tabular}




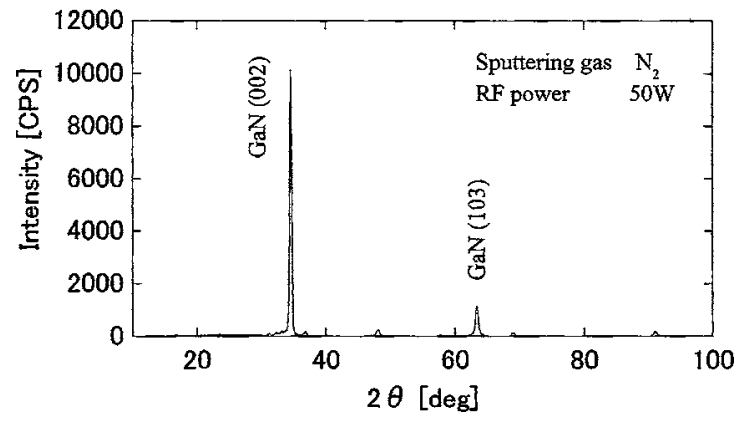

FIG. 4. X-ray diffraction pattern of the film deposited using $\mathrm{N}_{2}$ gas at total pressure of $20 \mathrm{mTorr}$ and a substrate temperature of $300^{\circ} \mathrm{C}$.

GaN. In terms of the dependence on the substrate temperature, increasing the temperature to $300{ }^{\circ} \mathrm{C}$ did not always improve crystallinity. The integrated intensity reaches a maximum at total pressures of 20-30 mTorr, and it drastically decreases at total pressures above $35 \mathrm{mTorr}$. The decrease in texture coefficient at pressures above $35 \mathrm{mTorr}$ is due to the change of the texturing from the (002) to (103) planes. At a pressure below 35 mTorr, however, the large variation in the intensity does not correspond to changes in the texturing. A comparison of the variation of the integrated intensity with that of FWHM indicates that poor crystallinity is related to a decrease in grain size. The GaN films with the highest degree of crystallinity are deposited at total pressures of 20-30 mTorr. The values of the rf power and the total pressure are comparable with those used by other researchers, i.e., Tansley et $a l^{3}$ ( $50 \mathrm{~W}, 33$ mTorr), Kubota et al. ${ }^{4}$ (50 W, 20 mTorr), Zembutsu and Kobayashi ${ }^{2}$ (40 W, $30-50$ mTorr), and Ross et al. ${ }^{5}$ (110 W, 25 mTorr). Figure 4 shows the XRD pattern of a film deposited at total pressure of $20 \mathrm{mTorr}$ and at a substrate temperature of $300{ }^{\circ} \mathrm{C}$.

\section{CONCLUSIONS}

When sputtering with Ar gas, the resputtering due to ion bombardment produces a film deficient in nitrogen with poor crystallinity. The film eventually becomes black and amorphous due to Ga atoms forming clusters in the film. Alternatively, when sputtering with $\mathrm{N}_{2}$ gas, the activated nitrogen atmosphere enhances nitrogen incorporation and prevents the destruction of the crystal structure, making the film stoichiometric. To achieve high crystallinity, the self-induced negative bias should be minimized by decreasing the rf power and increasing the total pressure. If the total pressure is too high, however, the kinetic energies of the $\mathrm{Ga}$ and $\mathrm{N}$ atoms are reduced by collisions with molecular nitrogen and the film becomes amorphous.

${ }^{1}$ H. J. Hovel and J. J. Cuomo, Appl. Phys. Lett. 20, 71 (1972).

${ }^{2}$ S. Zembutsu and M. Kobayashi, Thin Solid Films 129, 289 (1985).

${ }^{3}$ T. L. Tansley, R. J. Egan, and E. C. Horrigan, Thin Solid Films 164, 441 (1988).

${ }^{4}$ K. Kubota, Y. Kobayashi, and K. Fujimoto, J. Appl. Phys. 66, 2984 (1989).

${ }^{5}$ J. Ross, M. Rubin, and T. K. Gustafson, J. Mater. Res. 8, 2613 (1993).

${ }^{6}$ W. J. Meng and T. A. Perry, J. Appl. Phys. 76, 7824 (1994).

${ }^{7}$ P. Singh, J. M. Corbett, J. B. Webb, S. Charbonneau, F. Yang, and M. D. Robertson, J. Vac. Sci. Technol. A 16, 786 (1998).

${ }^{8}$ H. Tang, J. Webb, J. Bardwell, B. Leathem, S. Charbonneau, and S. Raymond, J. Electron. Mater. 29, 268 (2000).

${ }^{9}$ T. Kikuma, K. Tominaga, K. Furutani, K. Kusaka, T. Hanabusa, and T. Mukai, Vacuum 66, 233 (2002).

${ }^{10}$ J. L. Vossen and J. J. Cuomo, Thin Film Processes (Academic, New York, 1978), p. 50.

${ }^{11}$ T. Maruyama and T. Morishita, J. Appl. Phys. 76, 5809 (1994).

${ }^{12}$ J. C. Manifacier, J. Gasiot, and J. P. Fillard, J. Phys. E 9, 1002 (1976).

${ }^{13}$ H. P. Maruska and J. J. Tietjen, Appl. Phys. Lett. 15, 327 (1969).

${ }^{14}$ E. Ejder, Phys. Status Solidi A 6, 445 (1971).

${ }^{15}$ C. Barret and T. B. Massalski, Structure of Metals (Pergamon, Oxford, 1980), p. 204. 